\title{
Assessing the association between all-cause mortality and multiple aspects of individual social capital among the older Japanese
}

Jun Aida ${ }^{1,2^{*}}$, Katsunori Kondo ${ }^{3}$, Hiroshi Hirai ${ }^{3}$, S V Subramanian ${ }^{4}$, Chiyoe Murata ${ }^{5}$, Naoki Kondo ${ }^{6}$, Yukinobu Ichida ${ }^{3}$, Kokoro Shirai ${ }^{4,7}$ and Ken Osaka ${ }^{2}$

\begin{abstract}
Background: Few prospective cohort studies have assessed the association between social capital and mortality. The studies were conducted only in Western countries and did not use the same social capital indicators. The present prospective cohort study aimed to examine the relationships between various forms of individual social capital and all-cause mortality in Japan.

Methods: Self-administered questionnaires were mailed to subjects in the Aichi Gerontological Evaluation Study (AGES) Project in 2003. Mortality data from 2003 to 2008 were analyzed for 14,668 respondents. Both cognitive and structural components of individual social capital were collected: 8 for cognitive social capital (trust, 3; social support, 3; reciprocity, 2) and 9 for structural social capital (social network). Cox proportional hazard models stratified by sex with multiple imputation were used. Age, body mass index, self-rated health, current illness, smoking history, alcohol consumption, exercise, equivalent income and education were used as covariates.

Results: During 27,571 person-years of follow-up for men and 29,561 person-years of follow-up for women, 790 deaths in men and 424 in women were observed. In the univariate analyses for men, lower social capital was significantly related to higher mortality in one general trust variable, all generalised reciprocity variables and four social network variables. For women, lower social capital was significantly related to higher mortality in all generalised reciprocity and four social network variables. After adjusting for covariates, lower friendship network was significantly associated with higher all-cause mortality among men (meet friends rarely; $\mathrm{HR}=1.30,95 \% \mathrm{Cl}=$ 1.10-1.53) and women (having no friends; $\mathrm{HR}=1.81,95 \% \mathrm{Cl}=1.02-3.23$ ). Among women, lower general trust was significantly related to lower mortality (most people cannot be trusted; $\mathrm{HR}=0.65,95 \% \mathrm{Cl}=0.45-0.96$ ).
\end{abstract}

Conclusions: Friendship network was a good predictor for all-cause mortality among older Japanese. In contrast, mistrust was associated with lower mortality among women. Studies with social capital indices considering different culture backgrounds are needed.

\section{Background}

Few prospective cohort studies have assessed the association between social capital and mortality [1-5]. The studies did not use the same social capital indicators [1-5]. Some of these studies used proxy measures of social capital [6,7], such as crime rate [1], electoral participation [1,5] or volunteer activity [3-5]. There are

\footnotetext{
* Correspondence: j-aida@umin.ac.jp

'Department of Epidemiology and Public Health, University College London, London, UK

Full list of author information is available at the end of the article
}

several components of social capital, such as social network, participation, trust, reciprocity and volunteering [8]. Previous studies on social capital and mortality did not simultaneously use various components of social capital and their results were not fully consistent. In Finland, the association between mortality and individual social capital variables obtained by factor analysis (leisure participation, interpersonal trust and residential stability) was examined [2]. In men, leisure participation was associated with reduced all-cause mortality. In women, leisure participation and interpersonal trust
Ciomed Central

() 2011 Aida et al; licensee BioMed Central Ltd. This is an Open Access article distributed under the terms of the Creative Commons Attribution License (http://creativecommons.org/licenses/by/2.0), which permits unrestricted use, distribution, and reproduction in any medium, provided the original work is properly cited. 
were associated with reduced all-cause mortality. In a Swedish study, survival analyses showed that both neighbourhood social capital variables (election participation rate and crime rate) were significantly associated with mortality for males older than 65 years old but not for females [1]. Another study showed that living in a neighbourhood with the lowest level of social capital (volunteering, participation, political activities) was associated with significantly higher mortality than living in a neighbourhood with the highest level of social capital in England [5]. In contrast, among adults diagnosed and hospitalized with serious illnesses in the U.S, neighbourhood social capital (network density) was detrimental [4]. In addition, other neighbour social capital variables (social support, participation, volunteering, violence) did not significantly affect mortality [4]. In New Zealand, non-significant associations between neighbourhood social capital (volunteering) and mortality for both male and female were observed [3].

Studies on mortality and social capital have been conducted only in Western countries. However, social capital measurements developed in Western countries may not necessarily be equally applicable to Asian countries because of their different culture [9]. Although general trust has been broadly used as a measurement of social capital [10], it is known that intense ties within a family or group, often observed in collectivist cultures, prevent trust from developing beyond family or group boundaries [11-13]. In Japan, a relatively collectivist society with intense group ties, human relationships are based on mutual assurance within group members rather than mutual trust between members from different groups $[11,13]$. These cultural differences could potentially affect findings on the associations between social capital and health outcomes. In this respect, a social epidemiological study using various social capital indices in a non-Western cultural setting is important.

There is still debate about the precise definition and measurement of social capital $[8,14,15]$. Bourdieu defined social capital as "the aggregate of the actual or potential resources which are linked to possession of a durable network of more or less institutionalised relationships of mutual acquaintance and recognition"[16] and which focuses on the resources of individuals [8]. It is important to determine the association between individual social capital and health, because individual social capital indexes are components of aggregated measurements of community social capital [17]. Additionally, individual measures of social capital are not subject to the common problems arising from using area measurement in epidemiological studies, such as definition of a relevant areas $[18,19]$. No study has used various measures of individual social capital as a predictor of mortality in a non-Western country. The aim of the present prospective cohort study was to assess the influence of individual social capital on all-cause mortality among older Japanese.

\section{Methods}

\section{Study population and procedure}

The present analysis is based on the Aichi Gerontological Evaluation Study (AGES) Project data, an on-going prospective cohort study [20-24]. AGES investigates factors associated with the loss of health, including death and functional decline or cognitive impairment among older individuals. The study was undertaken in six municipalities covered the entire southern part of the Chita peninsula in Aichi Prefecture, Japan. During October one to 31 2003, a baseline mail questionnaire survey was administered. The follow-up started in November one 2003. Mortality data until May 2008 were obtained from 6 of the municipalities participating in AGES.

In 2003 , there were 274,750 people living in the six municipalities, $17.9 \%$ of them being 65 years or older. The sample was restricted to people who did not already have physical or cognitive disabilities, defined as receiving public long-term care insurance benefits. From the municipalities, 29,374 community-dwelling, aged 65 years or over people were selected randomly. From this sample population, 14,804 people responded to the baseline survey. Of the 14,804 respondents, we could link the mortality data and baseline survey data on 14,668 subjects, because 91 were ineligible due to death, functional decline or cognitive impairment before November 1, 2003, and for a further 45 there was no information that would allow linking of the mortality data. Some subjects did not apply to certification of long-term care needs though they had limitations in basic activities of daily living including walking, bathing and toilet use. We excluded them from the analysis to avoid potential confounding (1,358 of the 14,668 respondents). Finally, 13,310 subjects $(6,508$ men and 6,802 women.) were included in the analysis for this cohort study. Figure 1 shows the study profile. Characteristics of participants at baseline have been reported elsewhere [23,24]. The AGES protocol was reviewed and approved by the ethics committee in Research of Human Subjects at Nihon Fukushi University.

\section{Social capital variables}

Both cognitive and structural components $[8,10,17,25]$ of individual social capital were used. We basically followed Harpham's classification of social capital [17]. We used eight cognitive social capital variables, including general trust, social support and generalised reciprocity, and nine structural social capital variables, including social networks. 


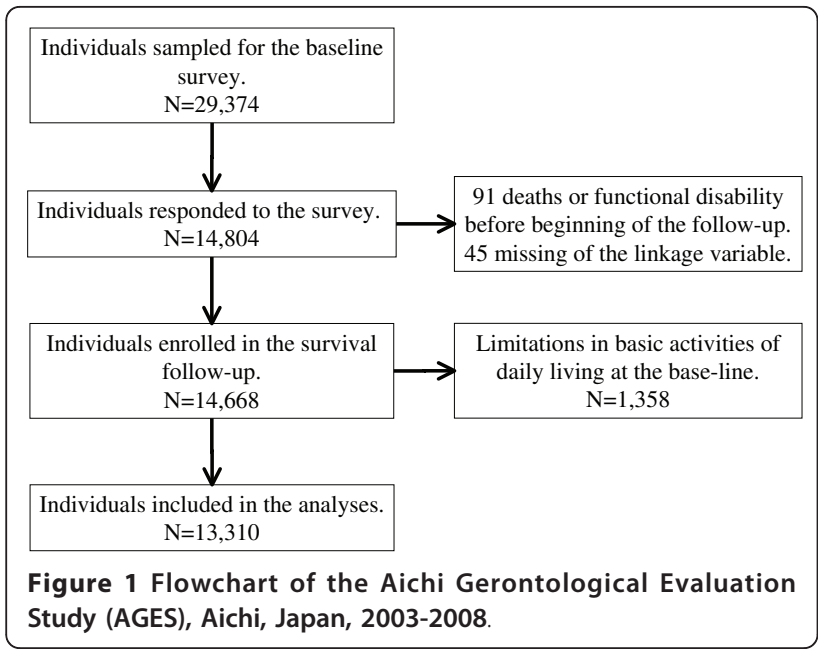

\section{Cognitive social capital}

General trust was measured by 3 questions: "Generally speaking, would you say that most people can be trusted?", "Do you think most people would try to take advantage of you if they got a chance?" and "Would you say that most of the time people try to be helpful?". For all these questions, response alternatives were "yes", "it depends" and "no".

Social support was measured by three questions, using a dichotomous answering choice (yes/no): "Do you have someone who listens to your concerns and complaints?", "Do you have someone who looks after you when you are sick and stay in bed for a few days?" and "Do you have someone who acknowledges your existence and value?".

Generalised reciprocity was measured by two questions, again with a dichotomous choice (yes/no): "Do you listen to someone's concerns and complaints?" and "Do you look after someone when he/she is sick and stays in bed for a few days?".

\section{Structural social capital}

Participation in community activities was used as an indication of social network. Respondents were asked whether they belonged to a (i) political organization or group, (ii) industrial or trade association, (iii) volunteer group, (iv) citizen or consumer group, (v) religious organization or group, (vi) sports group or club, (vii) neighbourhood association / senior citizen club / firefighting team and (viii) leisure activity group.

Social network was also measured by the question "How often do you meet your friends?" (response options: "almost everyday", "twice or three times a week", "once a week", "once or twice a month", "several times a year", "rarely" or "I have no friends"). For analyses purposes, the first four response options were integrated into one category, named "once or more/month".

\section{Covariates}

We also asked about socio-demographic characteristics, lifestyle and health condition and included the following in the analyses as covariates: age, sex, self-reported body mass index (BMI), self-rated health, present illness, smoking history, alcohol consumption, exercise, equivalent income and educational attainment [23]. Selfreported BMI was categorized into 4 groups (less than $18.5,18.5-24.9,25-29.9,30$ or more). Self-rated health was measured by a single question, "What is your current health status?: Excellent; Good; Fair; Poor". Present illnesses and present medical treatment were surveyed as follows: "Are you currently receiving any medical treatment?: I have no illnesses or disabilities; I have illness(es) or disability(ies) but need no treatment at the moment; I discontinued treatment of my own decision; I am currently receiving some treatment. Smoking history was recorded in 3 categories (never, quit or current) and alcohol consumption into 4 categories (nondrinker, do not drinking everyday, drinking $35 \mathrm{~g}$ of alcohol or less daily, or drink more than 35 g every day). Subjects were asked about how many minutes a day they walk - the exercise variable; less than 30 minutes, 30-60, 60-90 or more than 90 minutes or more. Years of educational attainment was grouped as less than 6 years, 6-9 years, 10-12 years and 13 years or more. Household income and number of household members were recorded and then equivalent income was calculated and categorized in Yen: less than 1,500,000; 1,500,0001,999,999; 2,000,000-2,499,999; 2,500,000-2,999,999; 3,000,000-3,499,999; 3,500,000-3,999,999; 4,000,0004,999,999; $500,000,000$ or higher.

\section{Mortality outcome}

Mortality obtained from the municipality government registry was treated as all-causes.

\section{Analysis}

We used Cox proportional hazard models to calculate the hazard ratio (HR) and 95\% confidential intervals $(95 \% \mathrm{CI})$ for all-cause mortality during the follow-up period. At first, we calculated univariate hazard ratios for mortality for the categories of each social capital variable. In the covariate adjusted models, we assessed the effect of each social capital variable on mortality with adjustment for age, BMI, self-rated health, current illness, smoking history, alcohol consumption, exercise, equivalent income and educational attainment. All analyses were stratified by sex.

In terms of analysis of missing data (numbers of missing responses in each variable are described in Table 1,2), we used the missing at random assumption for the relevant procedures. Multiple imputation with the MICE (multivariate imputation by chained 
Table 1 Characteristics of the subjects by mortality rate: the Aichi Gerontological Evaluation Study (AGES), Aichi, Japan, 2003-2008

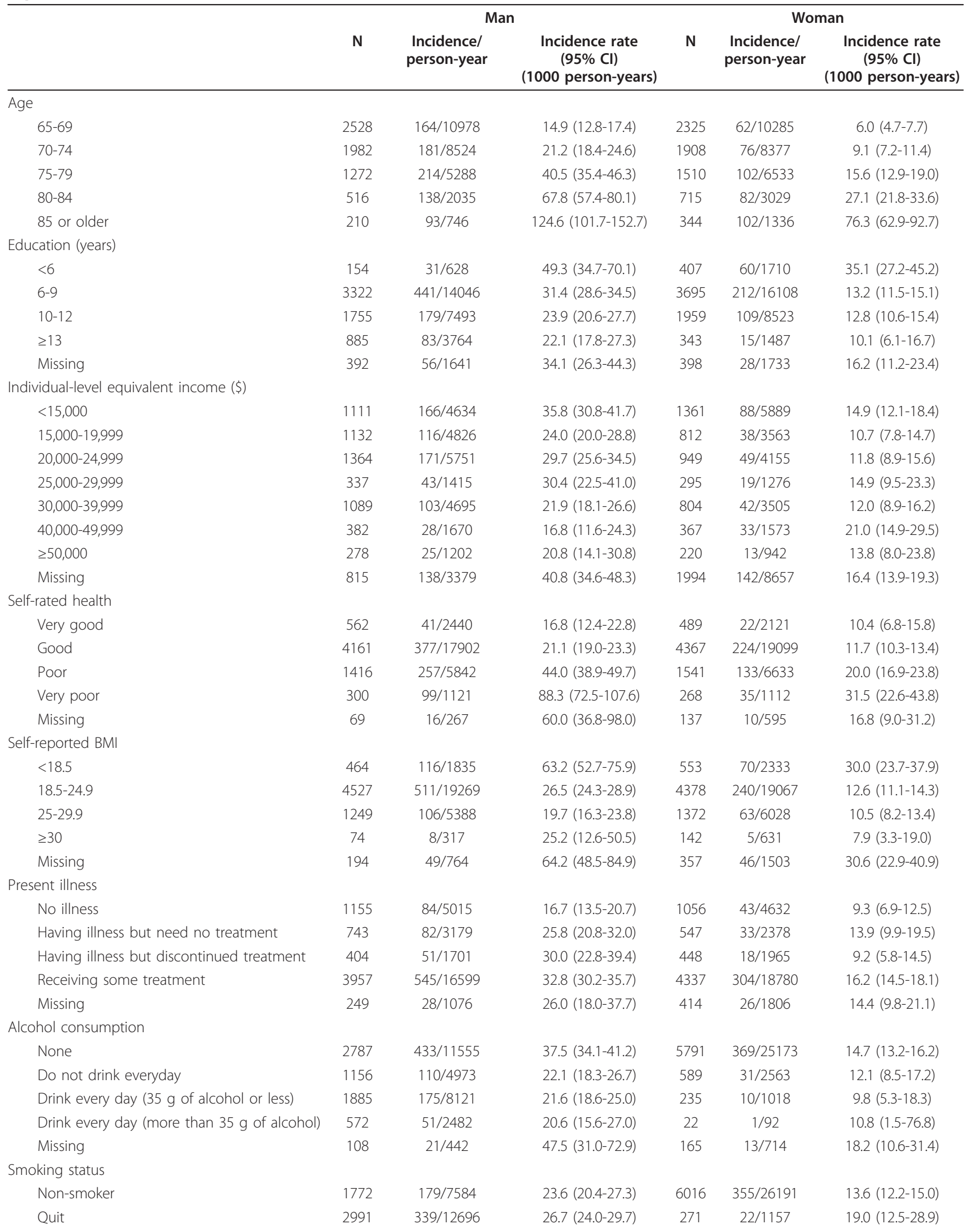


Table 1 Characteristics of the subjects by mortality rate: the Aichi Gerontological Evaluation Study (AGES), Aichi, Japan, 2003-2008 (Continued)

\begin{tabular}{|c|c|c|c|c|c|c|}
\hline Current & 1499 & $220 / 6297$ & $34.9(30.6-39.9)$ & 172 & 20/729 & $27.4(17.7-42.5)$ \\
\hline Missing & 246 & 52/994 & $52.3(39.9-68.6)$ & 343 & $27 / 1483$ & $18.2(12.5-26.5)$ \\
\hline \multicolumn{7}{|l|}{ Exercise } \\
\hline Walking less than 30 minutes walk a day & 2120 & $344 / 8789$ & $39.1(35.2-43.5)$ & 2176 & $165 / 9414$ & $17.5(15.0-20.4)$ \\
\hline Walking 30-60 minutes walk a day & 2222 & $246 / 9477$ & $26.0(22.9-29.4)$ & 2101 & $136 / 9105$ & $14.9(12.6-17.7)$ \\
\hline Walking 60-90 minutes walk a day & 906 & $74 / 3908$ & $18.9(15.1-23.8)$ & 769 & $25 / 3378$ & $7.4(5.0-11.0)$ \\
\hline Walking 90 or more minutes walk a day & 799 & $58 / 3472$ & $16.7(12.9-21.6)$ & 788 & $38 / 3443$ & $11.0(8.0-15.2)$ \\
\hline Missing & 461 & $68 / 1926$ & $35.3(27.8-44.8)$ & 968 & $60 / 4221$ & $14.2(11.0-18.3)$ \\
\hline Total & 6508 & $790 / 27572$ & $28.7(26.7-30.7)$ & 6802 & $424 / 29561$ & $14.3(13.0-15.8)$ \\
\hline
\end{tabular}

equations) method in STATA was used [26]. Cox proportional hazard models were independently applied for 10 copies of the data, each with missing values suitably imputed. Estimates of the variables were calculated to give a single mean estimate and adjusted standard errors according to Rubin's rules [27]. HRs and 95\%CI of the Cox proportional hazard models were calculated from these estimates. We show results both from multiple imputation analyses and analyses with complete data for each model (non-imputation analyses). STATA SE version 11.1 (Stata Corp, College Station, TX) was used and sample weights were applied when estimating HR.

\section{Results}

The average follow-up period was 4.29 years $(\mathrm{SD}=$ 0.75). During 27,571 person-years of follow-up for men and 29,561 person-years of follow-up for women, 790 all-cause deaths in men and 424 in women were observed. The incidence rate per 1000 person-years (IR) of death was 28.7 in men and 14.3 in women. Table 1 and 2 show the distribution of the number of deaths and IR according to covariates and social capital variables. Participants with low social capital in terms of generalised reciprocity and social network tended to have higher IR.

Table 3 shows the univariate and covariates adjusted mortality HRs for the different social capital variables among men. The results of multiple imputation models and non-imputation models were similar, particularly in the univariate models, but the $95 \%$ CIs were wider in most of the estimates obtained from the imputation models. In the univariate models using multiple imputation, lower social capital was significantly related to higher mortality in one general trust variable (people try to be helpful: $\mathrm{HR}=1.42(95 \% \mathrm{CI}=1.01-2.00))$, all generalised reciprocity variables (listen to someone's concerns: $\mathrm{HR}=1.59$ (95\%CI = 1.24-2.04); look after someone: HR $=1.49(95 \% \mathrm{CI}=1.12-2.00))$ and four social network variables (volunteer: $\mathrm{HR}=1.78(95 \% \mathrm{CI}=1.34-2.37)$; sports: $\mathrm{HR}=1.89(95 \% \mathrm{CI}=1.28-2.80)$; leisure: $\mathrm{HR}=$
$1.64(95 \% \mathrm{CI}=1.21-2.20)$; meet friends rarely: $\mathrm{HR}=1.99$ $(95 \% \mathrm{CI}=1.72-2.31))$. When adjusting these models for covariates, only one low social network variable was found to be related to higher mortality (meet friends rarely: $\mathrm{HR}=1.30(95 \% \mathrm{CI}=1.10-1.53))$, while the respective findings for two other social network variables (volunteering and leisure) were marginally not significant

Table 4 shows the univariate and covariates adjusted mortality HRs for the different social capital variables among women. The results of multiple imputation models and non-imputation models were also similar, particularly in the univariate models, but the 95\%CIs were wider in most of the estimates obtained from the imputation models. In the univariate multiple imputation models, lower social capital was significantly related to higher mortality in all generalised reciprocity variables (listen to someone's concerns: $\mathrm{HR}=2.31$ $(95 \% \mathrm{CI}=1.49-3.58)$ and look after someone: $\mathrm{HR}=$ $1.71(95 \% \mathrm{CI}=1.18-2.47))$ and four social network variables (sports: $\mathrm{HR}=2.32(95 \% \mathrm{CI}=1.41-3.82)$; leisure: $\mathrm{HR}=2.24(95 \% \mathrm{CI}=1.36-3.68)$; meet friends rarely: $\mathrm{HR}=2.41(95 \% \mathrm{CI}=1.31-4.45)$; having no friends: $\mathrm{HR}=3.40(95 \% \mathrm{CI}=2.10-5.52))$. In the covariate adjusted multiple imputation analysis, only one lower social network response related to higher mortality (having no friends: $\mathrm{HR}=1.81(95 \% \mathrm{CI}=1.02-3.23)$ ), while findings for one generalised reciprocity variable (listen to someone's concerns) and one social network variable (leisure) were marginally not significant. Interestingly, the response indicating lower social capital in one general trust variable was significantly related to lower mortality (most people cannot be trusted; $\mathrm{HR}=$ $0.65(95 \% \mathrm{CI}=0.45-0.96))$.

\section{Discussion}

To the best of our knowledge, this study is the first prospective cohort study to assess the relationships between various social capital measures and mortality. In addition, this is the first cohort study on the relationship 
Table 2 Characteristics of the subjects according to social capital and mortality rate: the Aichi Gerontological Evaluation Study (AGES), Aichi, Japan, 2003-2008

\begin{tabular}{|c|c|c|c|c|c|c|c|}
\hline & & & & Man & & & oman \\
\hline & & $\mathbf{N}$ & $\begin{array}{l}\text { Incidence/ } \\
\text { person- } \\
\text { year }\end{array}$ & $\begin{array}{c}\text { Incidence rate } \\
(95 \% \mathrm{Cl}) \\
(1000 \text { person-years })\end{array}$ & $\mathbf{N}$ & $\begin{array}{l}\text { Incidence/ } \\
\text { person- } \\
\text { year }\end{array}$ & $\begin{array}{c}\text { Incidence rate } \\
(95 \% \mathrm{Cl}) \\
(1000 \text { person-years }\end{array}$ \\
\hline General trust & & & & & & & \\
\hline Generally speaking, would you say that & Yes (High SC) & 2121 & 252/9007 & $28.0(24.7-31.7)$ & 1448 & $86 / 6290$ & $13.7(11.1-16.9)$ \\
\hline & Depends & 3667 & $422 / 15577$ & $27.1(24.6-29.8)$ & 4480 & 287/19452 & $14.8(13.1-16.6)$ \\
\hline & No (Low SC) & 545 & $80 / 2274$ & $35.2(28.3-43.8)$ & 667 & $31 / 2937$ & $10.6(7.4-15.0)$ \\
\hline & Missing & 175 & $36 / 713$ & $50.5(36.4-70.0)$ & 207 & 20/882 & $22.7(14.6-35.1)$ \\
\hline Would you say that most of the time & Yes (High SC) & 1954 & $227 / 8291$ & $27.4(24.0-31.2)$ & 1791 & $95 / 7817$ & $12.2(9.9-14.9)$ \\
\hline & Depends & 3710 & $412 / 15796$ & $26.1(23.7-28.7)$ & 4104 & $254 / 17826$ & $14.2(12.6-16.1)$ \\
\hline & No (Low SC) & 645 & $106 / 2675$ & $39.6(32.8-47.9)$ & 637 & $50 / 2760$ & $18.1(13.7-23.9)$ \\
\hline & Missing & 199 & $45 / 810$ & $55.5(41.5-74.4)$ & 270 & 25/1159 & $21.6(14.6-31.9)$ \\
\hline Do you think that most people would try & Yes (Low SC) & 797 & $101 / 3377$ & $29.9(24.6-36.4)$ & 616 & $40 / 2689$ & $14.9(10.9-20.3)$ \\
\hline & Depends & 3418 & $378 / 14536$ & $26.0(23.5-28.8)$ & 3558 & $210 / 15475$ & $13.6(11.9-15.5)$ \\
\hline & No (High SC) & 2093 & $263 / 8847$ & $29.7(26.3-33.5)$ & 2318 & $143 / 10073$ & $14.2(12.1-16.7)$ \\
\hline & Missing & 200 & $48 / 812$ & $59.1(44.5-78.4)$ & 310 & $31 / 1323$ & $23.4(16.5-33.3)$ \\
\hline Social support & & & & & & & \\
\hline Do you have someone who listens to & Yes (High SC) & 5267 & $605 / 22392$ & $27.0(24.9-29.3)$ & 5995 & $360 / 26087$ & $13.8(12.4-15.3)$ \\
\hline & No (Low SC) & 878 & $122 / 3671$ & $33.2(27.8-39.7)$ & 424 & $34 / 1819$ & $18.7(13.4-26.2)$ \\
\hline & Missing & 363 & $63 / 1508$ & $41.8(32.6-53.5)$ & 383 & $30 / 1655$ & $18.1(12.7-25.9)$ \\
\hline Do you have someone who looks after & Yes (High SC) & 5967 & $713 / 25308$ & $28.2(26.2-30.3)$ & 5988 & $372 / 26045$ & $14.3(12.9-15.8)$ \\
\hline & No (Low SC) & 258 & 29/1081 & $26.8(18.6-38.6)$ & 485 & $23 / 2112$ & $10.9(7.2-16.4)$ \\
\hline & Missing & 283 & $48 / 1182$ & $40.6(30.6-53.9)$ & 329 & 29/1404 & $20.6(14.3-29.7)$ \\
\hline Do you have someone who & Yes (High SC) & 5705 & $664 / 24243$ & $27.4(25.4-29.6)$ & 5849 & $357 / 25440$ & $14.0(12.7-15.6)$ \\
\hline & No (Low SC) & 433 & $65 / 1798$ & $36.2(28.4-46.1)$ & 379 & $30 / 1628$ & $18.4(12.9-26.3)$ \\
\hline & Missing & 370 & $61 / 1532$ & $39.8(31.0-51.2)$ & 574 & $37 / 2492$ & $14.8(10.8-20.5)$ \\
\hline Generalised reciprocity & & & & & & & \\
\hline Do you listen to someone's concerns and & Yes (High SC) & 4945 & $522 / 21122$ & $24.7(22.7-26.9)$ & 5348 & $282 / 23326$ & $12.1(10.8-13.6)$ \\
\hline & No (Low SC) & 1153 & $197 / 4748$ & $41.5(36.1-47.7)$ & 941 & $107 / 4000$ & $26.8(22.1-32.3)$ \\
\hline & Missing & 410 & 71/1701 & $41.7(33.1-52.7)$ & 513 & $35 / 2235$ & $15.7(11.2-21.8)$ \\
\hline Do you look after someone when he/she & Yes (High SC) & 5690 & $651 / 24190$ & $26.9(24.9-29.1)$ & 5785 & $324 / 25209$ & $12.9(11.5-14.3)$ \\
\hline & No (Low SC) & 461 & 78/1901 & $41.0(32.9-51.2)$ & 526 & $53 / 2242$ & $23.6(18.1-30.9)$ \\
\hline & Missing & 357 & $61 / 1481$ & $41.2(32.0-52.9)$ & 491 & $47 / 2109$ & $22.3(16.7-29.7)$ \\
\hline Social network & & & & & & & \\
\hline Political group participation & Yes (High SC) & 665 & $72 / 2848$ & $25.3(20.1-31.9)$ & 287 & $13 / 1250$ & $10.4(6.0-17.9)$ \\
\hline & No (Low SC) & 5230 & $605 / 22171$ & $27.3(25.2-29.6)$ & 5622 & $347 / 24445$ & $14.2(12.8-15.8)$ \\
\hline & Missing & 613 & $113 / 2553$ & $44.3(36.8-53.2)$ & 893 & $64 / 3866$ & $16.6(13.0-21.2)$ \\
\hline Industry group participation & Yes (High SC) & 952 & $108 / 4059$ & $26.6(22.0-32.1)$ & 293 & 6/1304 & $4.6(2.1-10.2)$ \\
\hline & No (Low SC) & 4869 & $556 / 20653$ & $26.9(24.8-29.3)$ & 5510 & $349 / 23929$ & $14.6(13.1-16.2)$ \\
\hline & Missing & 687 & $126 / 2860$ & $44.1(37.0-52.5)$ & 999 & $69 / 4327$ & $15.9(12.6-20.2)$ \\
\hline Volunteer group participation & Yes (High SC) & 642 & $45 / 2796$ & $16.1(12.0-21.6)$ & 574 & $22 / 2522$ & $8.7(5.7-13.2)$ \\
\hline
\end{tabular}


Table 2 Characteristics of the subjects according to social capital and mortality rate: the Aichi Gerontological Evaluation Study (AGES), Aichi, Japan, 2003-2008 (Continued)

\begin{tabular}{|c|c|c|c|c|c|c|c|}
\hline & No (Low SC) & 5122 & $613 / 21678$ & $28.3(26.1-30.6)$ & 5255 & $331 / 22829$ & $14.5(13.0-16.1)$ \\
\hline & Missing & 744 & 132/3097 & $42.6(35.9-50.5)$ & 973 & $71 / 4210$ & $16.9(13.4-21.3)$ \\
\hline \multirow[t]{3}{*}{ Citizen group participation } & Yes (High SC) & 245 & 28/1044 & $26.8(18.5-38.8)$ & 309 & $10 / 1368$ & $7.3(3.9-13.6)$ \\
\hline & No (Low SC) & 5465 & $622 / 23202$ & $26.8(24.8-29.0)$ & 5470 & $346 / 23752$ & $14.6(13.1-16.2)$ \\
\hline & Missing & 798 & $140 / 3326$ & $42.1(35.7-49.7)$ & 1023 & $68 / 4441$ & $15.3(12.1-19.4)$ \\
\hline \multirow[t]{3}{*}{ Religious group participation } & Yes (High SC) & 738 & $81 / 3152$ & $25.7(20.7-31.9)$ & 698 & $38 / 3031$ & $12.5(9.1-17.2)$ \\
\hline & No (Low SC) & 5021 & $580 / 21288$ & $27.2(25.1-29.6)$ & 5151 & $319 / 22391$ & $14.2(12.8-15.9)$ \\
\hline & Missing & 749 & $129 / 3131$ & $41.2(34.7-49.0)$ & 953 & $67 / 4139$ & $16.2(12.7-20.6)$ \\
\hline \multirow[t]{3}{*}{ Sports group participation } & Yes (High SC) & 1282 & $87 / 5602$ & $15.5(12.6-19.2)$ & 1152 & $36 / 5074$ & $7.1(5.1-9.8)$ \\
\hline & No (Low SC) & 4458 & $564 / 18776$ & $30.0(27.7-32.6)$ & 4642 & $319 / 20118$ & $15.9(14.2-17.7)$ \\
\hline & Missing & 768 & $139 / 3193$ & $43.5(36.9-51.4)$ & 1008 & $69 / 4369$ & $15.8(12.5-20.0)$ \\
\hline \multirow[t]{2}{*}{ Neighborhood group participation } & Yes (High SC) & 3445 & $384 / 14716$ & $26.1(23.6-28.8)$ & 3583 & $199 / 15657$ & $12.7(11.1-14.6)$ \\
\hline & No (Low SC) & 2531 & $308 / 10650$ & $28.9(25.9-32.3)$ & 2557 & 170/11058 & $15.4(13.2-17.9)$ \\
\hline \multirow[t]{3}{*}{ Avocation group participation } & Yes (High SC) & 1592 & $126 / 6882$ & $18.3(15.4-21.8)$ & 2054 & $75 / 9046$ & $8.3(6.6-10.4)$ \\
\hline & No (Low SC) & 4192 & $533 / 17671$ & $30.2(27.7-32.8)$ & 3819 & $285 / 16483$ & $17.3(15.4-19.4)$ \\
\hline & Missing & 724 & $131 / 3019$ & $43.4(36.6-51.5)$ & 929 & $64 / 4032$ & $15.9(12.4-20.3)$ \\
\hline \multirow[t]{6}{*}{ How often do you meet your friend? } & $\begin{array}{l}\text { Once or more/ } \\
\text { month }\end{array}$ & 4360 & $448 / 18691$ & $24.0(21.8-26.3)$ & 5301 & 296/23134 & $12.8(11.4-14.3)$ \\
\hline & $\begin{array}{l}\text { Several times/ } \\
\text { year }\end{array}$ & 1077 & $145 / 4513$ & $32.1(27.3-37.8)$ & 610 & $31 / 2654$ & $11.7(8.2-16.6)$ \\
\hline & Rarely & 752 & $141 / 3054$ & $46.2(39.1-54.5)$ & 529 & $59 / 2231$ & $26.4(20.5-34.1)$ \\
\hline & $\begin{array}{l}\text { Having no } \\
\text { friends }\end{array}$ & 151 & 24/620 & $38.7(25.9-57.7)$ & 125 & $22 / 508$ & $43.3(28.5-65.8)$ \\
\hline & Missing & 168 & $32 / 694$ & $46.1(32.6-65.2)$ & 237 & 16/1034 & $15.5(9.5-25.3)$ \\
\hline & & 6508 & 790/27572 & 28.7 (26.7-30.7) & 6802 & $424 / 29561$ & $14.3(13.0-15.8)$ \\
\hline
\end{tabular}

between social capital and mortality in a non-Western country. The present study showed that the structural social capital variable (friendship network) was a good predictor for all-cause mortality among older Japanese. Among men, it was the frequency of meetings with friends that was important, with those meeting their friends rarely having higher mortality, while was it was the lack of friends that was indicative of higher mortality among women. In addition, low general trust was related to lower mortality among women, suggesting that general trust has a different meaning among older Japanese women than among men.

Our results suggested the existence of culture differences in the association between trust and health. In addition, it is possible that the specific questions used to measure trust may also play a role. In our study, the question about general trust ("Generally speaking, would you say that most people can be trusted?") measures the trust for strangers, not group members [28]. In Japan, a relatively collectivist society with intense group ties, human relations are based on mutual assurance between group members rather than mutual trust between outgroup members $[11,13]$. The systems of mutual assurance, monitoring and sanctioning, within groups make the Japanese society safe and stable though closed
$[11,13]$. In such a society with strong ties, people can relatively easily obtain social support [29]. Though Japanese society is gradually changing recently because of globalisation, older people have lived in this traditional type of society for a long time throughout their lifecourse. Our results could suggest that Japanese older women who did not trust others would adapt well to the collectivist society with intense group ties and benefit from the society. In this Japanese older generation, men tended to work outside while women were predominantly housewives, therefore, men had to communicate with out-group members during their work and this may have contributed to developing their general trust towards strangers. In contrast, lower general trust measured by the question "Would you say that most of the time people try to be helpful?" tended to be associated with higher mortality among both men and women. This may be a more applicable question for measuring general trust among older Japanese, as this cohort may refer to their group members as "people" when answering this question. Previous cohort studies have not used general questions on trusting people to measure social capital. In Finland, a prospective study determined the beneficial effect of trust on all-cause mortality among women aged 30-99 years, not men [2]. 
Table 3 Univariate and covariate adjusted hazard ratios and $95 \%$ confidence intervals for all-cause mortality according to social capital

\begin{tabular}{|c|c|c|c|c|c|c|c|c|c|c|c|c|c|}
\hline & & \multicolumn{2}{|c|}{$\begin{array}{c}\text { Univariate } \\
\text { (imputation) }\end{array}$} & \multicolumn{3}{|c|}{$\begin{array}{c}\text { Univariate } \\
\text { (non-imputation) }\end{array}$} & \multicolumn{3}{|c|}{$\begin{array}{l}\text { Covariate } \\
\text { adjusted } \\
\text { (imputation) }\end{array}$} & \multicolumn{4}{|c|}{$\begin{array}{c}\text { Covariate } \\
\text { adjusted } \\
\text { (non-imputation) }\end{array}$} \\
\hline & & HR & $95 \% \mathrm{Cl}$ & & HR & $95 \% \mathrm{Cl}$ & & HR & $95 \% \mathrm{Cl}$ & & HR & $95 \% \mathrm{Cl}$ & \\
\hline \multicolumn{14}{|l|}{ General trust } \\
\hline \multirow{2}{*}{$\begin{array}{l}\text { Generally speaking, would you } \\
\text { say that most people can be } \\
\text { trusted? (Ref; Yes (High SC)) }\end{array}$} & Depends & 0.96 & $(0.77-1.20)$ & & 0.97 & $(0.80-1.17)$ & & 0.90 & $(0.69-1.16)$ & & 1.01 & $(0.77-1.33)$ & \\
\hline & No (Low SC) & 1.24 & $(0.91-1.70)$ & & 1.25 & $(0.96-1.63)$ & & 1.01 & $(0.74-1.36)$ & & 0.96 & $(0.65-1.42)$ & \\
\hline \multirow{2}{*}{$\begin{array}{l}\text { Would you say that most of } \\
\text { the time people try to be } \\
\text { helpful? (Ref; Yes (High SC)) }\end{array}$} & Depends & 1.00 & $(0.84-1.20)$ & & 1.01 & $(0.87-1.16)$ & & 0.92 & $(0.78-1.08)$ & & 1.00 & $(0.86-1.16)$ & \\
\hline & No (Low SC) & 1.42 & $(1.01-2.00)$ & * & 1.41 & $(1.06-1.87)$ & * & 1.20 & $(0.83-1.74)$ & & 1.06 & $(0.69-1.63)$ & \\
\hline $\begin{array}{l}\text { Do you think most people } \\
\text { would try to take advantage } \\
\text { of you if they got a chance? } \\
\text { (Ref; Yes (Low SC)) }\end{array}$ & Depends & 0.91 & $(0.63-1.33)$ & & 0.92 & $(0.65-1.30)$ & & 1.01 & $(0.61-1.68)$ & & 1.00 & $(0.57-1.73)$ & \\
\hline \multicolumn{14}{|l|}{ Social support } \\
\hline $\begin{array}{l}\text { Do you have someone who } \\
\text { listens to your concerns and } \\
\text { complaints? (Ref; Yes (High SC)) }\end{array}$ & No (Low SC) & 1.33 & $(0.79-2.23)$ & & 1.33 & $(0.80-2.20)$ & & 1.09 & $(0.61-1.95)$ & & 1.17 & $(0.63-2.15)$ & \\
\hline $\begin{array}{l}\text { Do you have someone who } \\
\text { looks after you when you are } \\
\text { sick and stay in bed for a few } \\
\text { days? (Ref; Yes (High SC)) }\end{array}$ & No (Low SC) & 1.06 & $(0.70-1.61)$ & & 1.06 & $(0.71-1.58)$ & & 0.84 & $(0.58-1.22)$ & & 0.87 & $(0.50-1.52)$ & \\
\hline $\begin{array}{l}\text { Do you have someone who } \\
\text { acknowledges your existence } \\
\text { and value? (Ref; Yes (High SC)) }\end{array}$ & No (Low SC) & 1.49 & $(0.99-2.25)$ & & 1.48 & $(0.95-2.30)$ & & 1.18 & $(0.67-2.08)$ & & 1.33 & $(0.70-2.54)$ & \\
\hline \multicolumn{14}{|l|}{ General reciprocity } \\
\hline $\begin{array}{l}\text { Do you listen to someone's } \\
\text { concerns and complaints? (Ref; } \\
\text { Yes (High SC)) }\end{array}$ & No (Low SC) & 1.59 & $(1.24-2.04)$ & * & 1.58 & $(1.31-1.91)$ & $*$ & 1.27 & $(0.95-1.70)$ & & 1.03 & $(0.70-1.51)$ & \\
\hline $\begin{array}{l}\text { Do you look after someone } \\
\text { when he/she is sick and stays } \\
\text { in bed for a few days? (Ref; Yes } \\
\text { (High SC)) }\end{array}$ & No (Low SC) & 1.49 & $(1.12-2.00)$ & * & 1.44 & $(1.13-1.83)$ & * & 1.01 & $(0.78-1.32)$ & & 0.83 & $(0.70-0.98)$ & \\
\hline \multicolumn{14}{|l|}{ Social network } \\
\hline $\begin{array}{l}\text { Political organization or group } \\
\text { (Ref; yes) }\end{array}$ & No (Low SC) & 1.14 & $(0.83-1.56)$ & & 1.11 & $(0.85-1.46)$ & & 0.99 & $(0.71-1.39)$ & & 1.11 & $(0.83-1.49)$ & \\
\hline $\begin{array}{l}\text { Industrial or trade association } \\
\text { (Ref; yes) }\end{array}$ & No (Low SC) & 1.04 & $(0.72-1.51)$ & & 1.02 & $(0.80-1.29)$ & & 0.88 & $(0.59-1.30)$ & & 0.91 & $(0.62-1.35)$ & \\
\hline Volunteer group (Ref; yes) & No (Low SC) & 1.78 & $(1.34-2.37)$ & * & 1.75 & $(1.39-2.21)$ & $*$ & 1.30 & $(0.95-1.77)$ & & 1.51 & $(1.19-1.91)$ & \\
\hline $\begin{array}{l}\text { Citizen or consumer group } \\
\text { (Ref; yes) }\end{array}$ & No (Low SC) & 1.05 & $(0.59-1.86)$ & & 0.98 & $(0.57-1.68)$ & & 0.79 & $(0.43-1.47)$ & & 0.95 & $(0.37-2.40)$ & \\
\hline $\begin{array}{l}\text { Religious organization or group } \\
\text { (Ref; yes) }\end{array}$ & No (Low SC) & 1.10 & $(0.77-1.56)$ & & 1.11 & $(0.79-1.56)$ & & 1.21 & $(0.86-1.70)$ & & 1.30 & $(1.06-1.58)$ & \\
\hline Sports group or club (Ref; yes) & No (Low SC) & 1.89 & $(1.28-2.80)$ & * & 1.98 & $(1.52-2.58)$ & $*$ & 1.32 & $(0.78-2.21)$ & & 1.44 & $(1.10-1.88)$ & \\
\hline $\begin{array}{l}\text { Neighbourhood association / } \\
\text { Senior citizen club / Fire- } \\
\text { fighting team (Ref; yes) }\end{array}$ & No (Low SC) & 1.16 & $(0.94-1.42)$ & & 1.15 & $(0.95-1.39)$ & & 1.12 & $(0.90-1.40)$ & & 1.20 & $(0.80-1.81)$ & \\
\hline Leisure activity group (Ref; yes) & No (Low SC) & 1.64 & $(1.21-2.20)$ & * & 1.59 & $(1.40-1.81)$ & * & 1.29 & $(0.94-1.77)$ & & 1.27 & $(1.04-1.55)$ & \\
\hline \multirow{3}{*}{$\begin{array}{l}\text { How often do you meet your } \\
\text { friends? (Ref; Once or more/ } \\
\text { month) }\end{array}$} & Several/year & 1.26 & $(0.96-1.67)$ & & 1.26 & $(0.99-1.60)$ & & 1.09 & $(0.77-1.56)$ & & 1.06 & $(0.75-1.48)$ & \\
\hline & Rarely & 1.99 & $(1.72-2.31)$ & * & 1.99 & $(1.75-2.25)$ & $*$ & 1.30 & $(1.10-1.53)$ & * & 1.38 & $(1.28-1.49)$ & \\
\hline & $\begin{array}{l}\text { Having no } \\
\text { friend }\end{array}$ & 1.43 & $(0.79-2.56)$ & & 1.41 & $(0.90-2.20)$ & & 0.77 & $(0.47-1.26)$ & & 0.49 & $(0.19-1.26)$ & \\
\hline
\end{tabular}

Multiple imputation Cox proportional hazard models: the Aichi Gerontological Evaluation Study (AGES), Aichi, Japan, 2003-2008, Men'.

${ }^{1}$ Adjusted for age, BMI, self-rated health, current illness, smoking history, alcohol consumption, exercise, equivalent income and education.

* Statistically significant variable $(p<0.05)$. 
Table 4 Univariate and covariate adjusted hazard ratios and $95 \%$ confidence intervals for all-cause mortality according to social capital

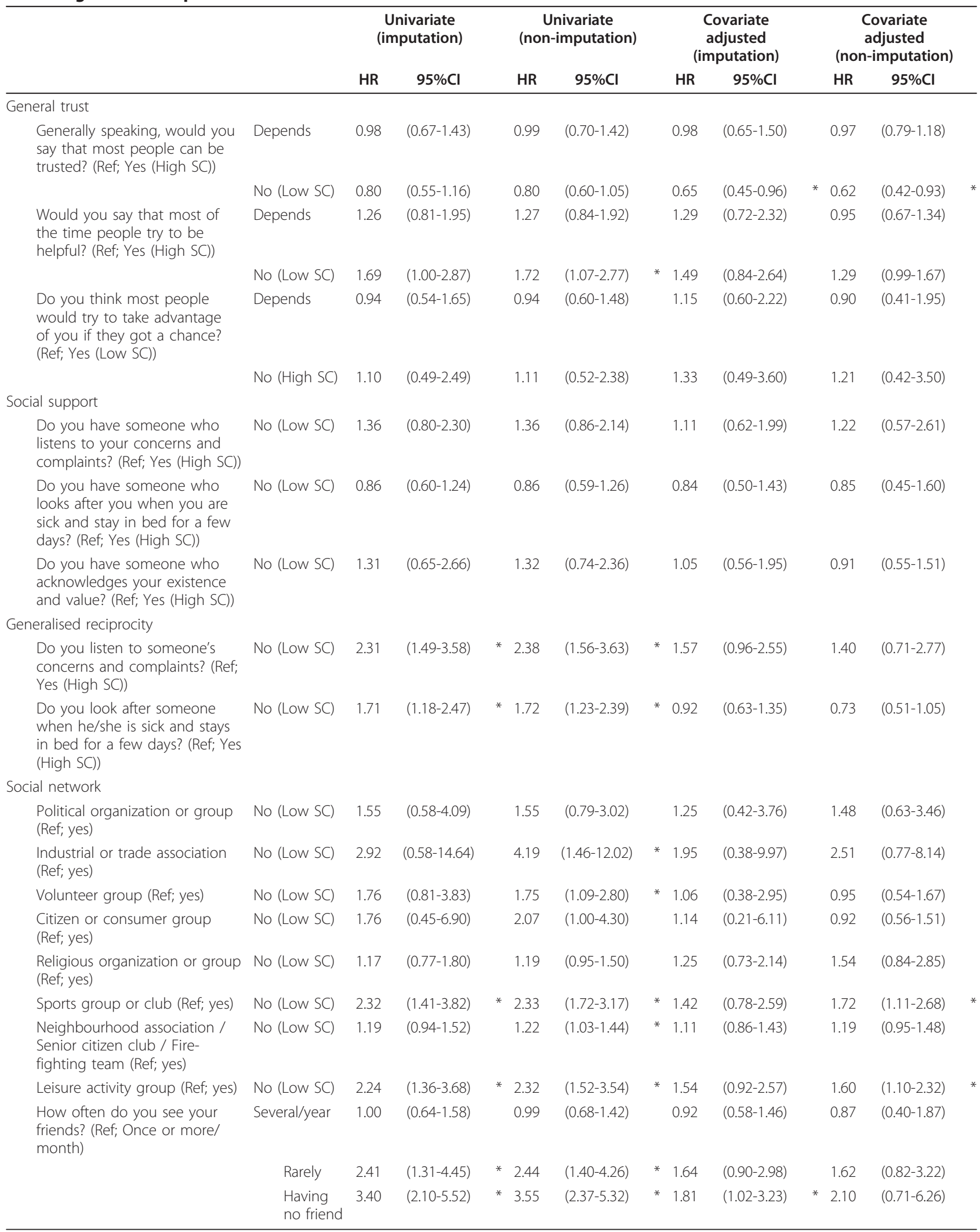

Multiple imputation Cox proportional hazard models: the Aichi Gerontological Evaluation Study (AGES), Aichi, Japan, 2003-2008, Women 1.

${ }^{1}$ Adjusted for age, BMI, self-rated health, current illness, smoking history, alcohol consumption, exercise, equivalent income and education.

* Statistically significant variable $(p<0.05)$. 
Their measure of trust was based on the number of and trust in close friends. In this study, we did not use the factor/principal component analysis to check the association between detailed, not combined, social capital variables and mortality. As the results, various social capital variables were included into the models and different association of trust questions on mortality were shown though this method had the possibility of a type 1 error. Further prospective research assessing trust and mortality with considering various culture backgrounds is needed.

Our results are partially consistent with those of previous studies. Social network and social support are positively associated with health. A meta-analysis of social relationships and mortality determined that strong structural social relationships (social network) and functional social relationships (social support) increased the likelihood of survival [30]. In line with this, our study showed significant associations between friendship network and mortality (meet friends rarely for men; $\mathrm{HR}=$ 1.30 (95\%CI = 1.10-1.53), having no friends for women; $\mathrm{HR}=1.81$ (95\%CI = 1.02-3.23)); however, social support was not significantly associated with mortality. Although we considered diagnosed diseases and excluded from our study people with limitations in basic activities of daily living, it is possible that people included in the study may have had latent fatal diseases and consequently needed some help; this may have affected our results about social support and mortality. The concept of generalised reciprocity is based on the assumption that when people provide resources, good turns will be repaid at some unspecified time in the future, perhaps even by an stranger [31]. It does not entail tit-for-tat calculations in which individuals can be sure that a good turn will be repaid quickly and automatically [31]. Therefore, we used variables about the provision of social support as generalised reciprocity variables. In our study, generalised reciprocity showed marginal though non-significant association with mortality $(\mathrm{HR}=1.27$ $(95 \% \mathrm{CI}=0.95-1.70)$ for men and $\mathrm{HR}=1.57$ (95\% CI $=$ 0.96-2.55) for women). A prospective cohort study in Finland showed that leisure participation was significantly though marginally associated with reduced allcause mortality $(\mathrm{HR}=0.94(95 \% \mathrm{CI}=0.89-1.00)$ for men and $\mathrm{HR}=0.96$ (95\%CI $=0.91-1.00)$ for women). In our study, covariate adjusted HRs of leisure participation were again marginal, though non-significant $(\mathrm{HR}=1.29$ $(95 \% \mathrm{CI}=0.94-1.77)$ for men and $\mathrm{HR}=1.54(95 \% \mathrm{CI}=$ 0.92-2.57) for women). The meaning of volunteering varies in the societies of different cultures [8] and relationships between volunteering and mortality are not consistent across studies [3-5]. In our study, covariate adjusted HR of volunteer participation was marginal though non-significant for men $(\mathrm{HR}=1.30(95 \% \mathrm{CI}=$
0.95-1.77) ) and non-significant for women $(\mathrm{HR}=1.06$ $(95 \% \mathrm{CI}=0.38-2.95))$.

There are several plausible pathways linking social capital to health [32]. At first, social capital may affect individual health by influencing health-related behaviours through promotion of more rapid diffusion of health information and by exerting social control over deviant health-related behaviours [32]. Second, higher social capital may promote health by increasing access to local services and amenities [32]. Good access to service such as transportation, clinics and community health centres could improve health. Third, there are associations between social capital and psychological distress $[33,34]$. Social networks and social support can buffer the negative effects of life events on mental health [34]. Fourth, the communities with higher social capital produce more egalitarian patterns of political participation that result in the implementation of policies which ensure the security of all its members [32].

The results of this study have important public health implications. Among older Japanese, structural social capital variable related to friendship network were found to be significantly associated with mortality regardless of various covariates. This result suggests the possibility that public investment to promote social network may reduce the mortality among older people.

Our study has a number of limitations and strengths. The follow-up period (4.29 years) was relatively short. There was a potential bias caused by latent fatal disease though we considered diagnosed diseases and limitations in basic activities of daily living at baseline. In addition, the response rate was 50.4\%; therefore, the results may have been affected by selection bias. Hanibuchi et al. previously conducted ecological analysis that assessed associations between community-level social capital and response rate using another data set from the AGES project and found that higher response rates were significantly associated with higher social capital [35]. Therefore, respondents of this study might have higher social capital than non-respondents. Although our results showed significant effects of some dimensions of social capital on all-cause mortality, this low response rate might have attenuated that association. In addition, compared with government data, our study respondents tended to be younger. It could be argued that healthier and younger people tend to respond to our questionnaire while people with higher risks of mortality tend to not participate. If so, this might have contributed to an underestimation of the association between poor social capital and mortality. As a strength, the present study used various social capital variables. Although the validity and reliability of the social capital variables were not been directly examined, a previous study using AGES 
project data checked the association between social capital variables based on our survey and voting rate, rate of volunteer registration and rate of social participation based on public social survey data [35]. Mean response of trust variable measured by our survey significantly associated with rate of volunteer registration in each community. Similarly, social network variables were significantly associated with voting rate.

\section{Conclusions}

In conclusion, friendship network, a measure of individual social capital, was a good predictor for allcause mortality among older Japanese. In addition, low general trust was related to lower mortality among women. Further studies examining the different effect of social capital between Western and non-Western countries are needed.

\begin{abstract}
Acknowledgements
This study used data from the Aichi Gerontological Evaluation Study (AGES). This survey was conducted by the Nihon Fukushi University Center for Wellbeing and Society as one of their research projects, and supported by a grant of Strategic Research Foundation Grant-aided Project for Private Universities from Ministry of Education, Culture, Sport, Science, and Technology, Japan (MEXT), 2009-2013.

The authors wish to thank Dr. Tomoya Hanibuchi and Dr. Georgios Tsakos for helpful comments on an earlier draft.
\end{abstract}

\section{Author details}

${ }^{1}$ Department of Epidemiology and Public Health, University College London, London, UK. ²Department of International and Community Oral Health, Tohoku University Graduate School of Dentistry, Sendai, Japan. ${ }^{3}$ Center for Well-being and Society, Nihon Fukushi University, Nagoya, Japan. ${ }^{4}$ Department of Society, Human Development, and Health, Harvard School of Public Health, Boston, USA. ${ }^{5}$ Department of Community Health and Preventive Medicine, Hamamatsu University School of Medicine, Hamamatsu, Japan. ${ }^{6}$ Department of Health Sciences, Interdisciplinary Graduate School of Medicine and Engineering, University of the Yamanashi, Chuo-shi, Japan. ${ }^{7}$ University of the Ryukyus, Naha, Japan.

\section{Authors' contributions}

JA had the idea for the study, participated in its design, performed the statistical analysis and drafted the manuscript as a principal author. KK helped develop the idea of the study, participated in acquiring the data and with design, and edited the manuscript. $\mathrm{HH}$ participated in acquiring the data and critically revising the manuscript. SVS participated in design of study, data analysis and critically revised the manuscript. CM, NK, YI, KS and $\mathrm{KO}$ participated in design of study and critically revised the manuscript. All authors read and approved the final manuscript.

\section{Competing interests}

The authors declare that they have no competing interests.

Received: 7 December 2010 Accepted: 25 June 2011 Published: 25 June 2011

\section{References}

1. Islam MK, Gerdtham UG, Gullberg B, Lindstrom M, Merlo J: Social capital externalities and mortality in Sweden. Econ Hum Biol 2008, 6(1):19-42.

2. Hyyppa MT, Maki J, Impivaara O, Aromaa A: Individual-level measures of social capital as predictors of all-cause and cardiovascular mortality: a population-based prospective study of men and women in Finland. Eur J Epidemiol 2007, 22(9):589-597.
3. Blakely T, Atkinson J, Ivory V, Collings S, Wilton J, Howden-Chapman P: No association of neighbourhood volunteerism with mortality in New Zealand: a national multilevel cohort study. Int J Epidemiol 2006, 35(4):981-989.

4. Wen M, Cagney KA, Christakis NA: Effect of specific aspects of community social environment on the mortality of individuals diagnosed with serious illness. Soc Sci Med 2005, 61(6):1119-1134.

5. Mohan J, Twigg L, Barnard S, Jones K: Social capital, geography and health: a small-area analysis for England. Soc Sci Med 2005, 60(6):1267-1283.

6. Kawachi I: Commentary: social capital and health: making the connections one step at a time. Int J Epidemio/ 2006, 35(4):989-993.

7. Paldam M: Social capital: one or many? Definition and measurement. Journal of Economic Surveys 2000, 14(5):629-653.

8. Baum FE, Ziersch AM: Social capital. J Epidemiol Community Health 2003, 57(5):320-323.

9. Kawachi I: Foreword. In Health Inequalities in Japan: An Empirical Study of Older People. Edited by: Kondo K. Melbourne; 2010:.

10. Islam MK, Merlo J, Kawachi I, Lindstrom M, Gerdtham UG: Social capital and health: does egalitarianism matter? A literature review. Int J Equity Health 2006, 5:3.

11. Yamagishi T, Cook KS, Watabe M: Uncertainty, trust, and commitment formation in the United States and Japan. Am J Sociol 1998, 104(1):165-194.

12. Fukuyama F: Low-trust societies and the paradox of family values. Trust: Social virtue and the creation of property New York: Free press; 1995, 59-145.

13. Yamagishi T, Yamagishi M: Trust and Commitment in the United-States and Japan. Motiv Emotion 1994, 18(2):129-166.

14. Kawachi I, Subramanian SV, Kim D: Social Capital and Health: A Decade of Progress and Beyond. In Social Capital and Health. Edited by: Kawachi I, Subramanian SV, Kim D. New York: Springer; 2008:1-26.

15. Carpiano RM: Toward a neighborhood resource-based theory of social capital for health: can Bourdieu and sociology help? Soc Sci Med 2006, 62(1):165-175.

16. Bourdieu P: The forms of capital. In The handbook of theory and research for the sociology of education. Edited by: Richardson J. New York: Greenwood Press; 1986:241-258.

17. Harpham T: The Measurement of Community Social Capital Through Surveys. In Social Capital and Health. Edited by: Kawachi I, Subramanian SV, Kim D. New York: Springer; 2008:51-62.

18. Roux AVD: The study of group-level factors in epidemiology: Rethinking variables, study designs, and analytical approaches. Epidemiologic Reviews 2004, 26:104-111.

19. Van der Gaag M, Webber M: Measurement of individual social capital: questions, instruments and measures. In Social Capital and Health. Edited by: Kawachi I, Subramanian SV, Kim D. New York: Springer; 2008:29-49.

20. Kondo N, Kawachi I, Hirai H, Kondo K, Subramanian SV, Hanibuchi T, Yamagata Z: Relative deprivation and incident functional disability among older Japanese women and men: prospective cohort study. J Epidemiol Community Health 2009, 63(6):461-467.

21. Aida J, Hanibuchi T, Nakade M, Hirai H, Osaka K, Kondo K: The different effects of vertical social capital and horizontal social capital on dental status: a multilevel analysis. Soc Sci Med 2009, 69(4):512-518.

22. Murata C, Kondo K, Hirai H, Ichida Y, Ojima T: Association between depression and socio-economic status among community-dwelling elderly in Japan: the Aichi Gerontological Evaluation Study (AGES). Health Place 2008, 14(3):406-414.

23. Kondo K: Health Inequalities in Japan: An Empirical Study of the Older People Melbourne: Trans Pacific Press; 2010.

24. Nishi A, Kondo K, Hirai H, Kawachi I: Cohort Profile: The AGES 2003 Cohort Study in Aichi, Japan. J Epidemiol 2011, 21(2):151-157.

25. Harpham T, Grant E, Thomas E: Measuring social capital within health surveys: key issues. Health Policy Plan 2002, 17(1):106-111.

26. Nur U, Shack LG, Rachet B, Carpenter JR, Coleman MP: Modelling relative survival in the presence of incomplete data: a tutorial. Int J Epidemiol 2010, 39(1):118-128.

27. Rubin D: Multiple imputation for non-response in surveys New York: John Wiley; 1987.

28. Uslaner EM: The Moral Foundation of Trust Cambridge: Cambridge University Press; 2002. 
29. Lin N: Social Capital: A Theory of Social Structure and Action Cambridge Cambridge University Press; 2001

30. Holt-Lunstad J, Smith TB, Layton JB: Social relationships and mortality risk: a meta-analytic review. PLoS Med 2010, 7(7):e1000316.

31. Newton K: Social capital and democracy. American Behavioral Scientist 1997, 40:575-586.

32. Kawachi I, Berkman L: Social cohesion, social capital, and health. In Social epidemiology. Edited by: Berkman L, Kawachi I. New York: Oxford University Press; 2000:174-190.

33. Phongsavan P, Chey T, Bauman A, Brooks R, Silove D: Social capital, socioeconomic status and psychological distress among Australian adults. Soc Sci Med 2006, 63(10):2546-2561.

34. Kawachi I, Berkman LF: Social ties and mental health. J Urban Health 2001, 78(3):458-467.

35. Hanibuchi T, Hirai H, Kondo K, Maeda S, Aida J, Ichida Y: A study of social capital indices in area level (in Japanese). Journal of Health and Welfare Statistics 2009, 56(1):26-32.

\section{Pre-publication history}

The pre-publication history for this paper can be accessed here:

http://www.biomedcentral.com/1471-2458/11/499/prepub

\section{doi:10.1186/1471-2458-11-499}

Cite this article as: Aida et al:: Assessing the association between allcause mortality and multiple aspects of individual social capital among the older Japanese. BMC Public Health 2011 11:499.

\section{Submit your next manuscript to BioMed Central} and take full advantage of:

- Convenient online submission

- Thorough peer review

- No space constraints or color figure charges

- Immediate publication on acceptance

- Inclusion in PubMed, CAS, Scopus and Google Scholar

- Research which is freely available for redistribution 